\title{
The torsion of a wandering pelvic spleen: A case report
} Francesco Feroci*1, Egidio Miranda2 ${ }^{2}$ Luca Moraldi ${ }^{2}$ and Renato Moretti ${ }^{2}$

Address: ${ }^{1}$ Division of General Surgery, Ospedale Misericordia e Dolce, P.za dell'ospedale 5, 59100 Prato, Italy and ${ }^{2}$ Division of General Surgery, AOU Careggi, V.le Morgagni 85, 50100 Firenze, Italy

Email: Francesco Feroci* - fferoci@yahoo.it; Egidio Miranda - emiranda@libero.it; Luca Moraldi - violamor@tin.it; Renato Moretti - renatomoretti@virgilio.it

* Corresponding author

Published: 10 September 2008

Cases Journal 2008, I:149 doi:10.1186/1757-1626-1-149

This article is available from: http://www.casesjournal.com/content/I/I/149

(C) 2008 Feroci et al; licensee BioMed Central Ltd.

This is an Open Access article distributed under the terms of the Creative Commons Attribution License (http://creativecommons.org/licenses/by/2.0), which permits unrestricted use, distribution, and reproduction in any medium, provided the original work is properly cited.

Received: 20 August 2008

Accepted: 10 September 2008

\begin{abstract}
A 15 years old patient was taken to the operative room for an explorative laparotomy due to abdominal pain and a pelvic spleen at preoperative computed tomography: was pointed out the absence of all splenic ligamentous attachments and short gastric vessels with a consequently dislocation of a bigger and congested spleen in the pelvis. This organ, wrapped in the omentum, was in a serious ischemic suffering due to a 720 degrees clock torsion around its exceptionally long pedicle (about $20 \mathrm{~cm}$ ); besides was confirmed pancreatic body and tail ectopy. Following the derotation, the volume of the organ has decreased but became fixed in above norm dimensions. $A$ total splenectomy was executed.
\end{abstract}

\section{Case presentation}

A 15 year old otherwise healthy Caucasian male student (52 kilograms of weight, 170 centimeters of height, no smoker, no drinking alcohol, not assuming medications with no significative family history) presented to the Emergency Department with a 24 hours abdominal pain and increase of his abdominal girth. The pain was noncontinuous, poorly localized, and was non-colicky and non-radiating in nature. There was no history of vomiting, bowel or urinary symptoms. Over the prior 2 months, he reported one other similar episode that had resolved spontaneously. He was afebrile and his vital signs were stable. Abdominal examination revealed marked diffuse abdominal tenderness and guarding. A large hypogastric abdominal mass was palpable. Urinalysis and urine culture were normal; he had a white cell count of $19.4 \times 10^{9} /$ $\mathrm{L}$, hemoglobin $11.0 \mathrm{~g} / \mathrm{dL}$ and platelets $410 \times 10^{9} / \mathrm{L}$ ). On abdominal sonography, no spleen could be demonstrated in the normal position; the left upper quadrant was filled with bowel loops. An enlarged spleen extending from lower-polar region of the left kidney to the pelvis was seen. A large hypoechoic area was seen, suggestive of infarction, with a streak of perisplenic fluid. Ultrasonography demonstrated no blood flow in the splenic vein and in the splenic artery. Subsequent contrast-enhanced CT scan also showed absence of the spleen in the left upper quadrant as well as an enlarged spleen in the left lumbar and iliac region. The splenic parenchyma showed poorly, inhomogenous enhancing areas suggestive of infarction. The splenic vein was dilatated and showed a non-enhancing filling defect near the hilum, indicating the presence of a thrombosis. The splenic vessels, pancreatic tail, and the surrounding fat formed a whorled appearance, supermedial to the splenic hilum, that was suggestive of torsion.

The patient underwent exploratory laparotomy through a midline incision. This revealed the absence of all splenic ligamentous attachments and short gastric vessels with a consequently dislocation of a bigger and congested spleen in the pelvis. This organ, wrapped in the omentum, was in 
a serious ischemic suffering due to a $720^{\circ}$ clock torsion around its exceptionally long pedicle $(\approx 20 \mathrm{~cm})$; besides was confirmed pancreatic body and tail ectopy (Figure 1). Following the derotation, the volume of the organ has decreased but became fixed in above norm dimensions (Figure 2). A total splenectomy was performed in view of a symptomatic wandering spleen, with hypersplenism and portal hypertension. The patient's post-operative course was uneventful.

\section{Discussion}

A wandering spleen is a rare but well-known entity. The incidence is $<0.2 \%$. It is more common in females than males in an adult population [1]. Acute, chronic or intermittent torsion of the spleen is the major complication of an abnormally mobile spleen, the "wandering spleen." The increased mobility of the spleen results from absence or laxity of the supporting ligaments (gastrosplenic and splenorenal ligaments) that normally anchor the spleen in its normal position [2].

The clinical presentation of a wandering spleen can be variable. Affected patients may be asymptomatic and this condition may be discovered incidentally as an abdominal mass on physical examination or on imaging for other unrelated reasons. Patients may have mild intermittent abdominal pain due to splenic congestion with intermittent torsion and spontaneous detorsion, or may present with an acute abdomen due to torsion of the splenic pedicle with subsequent infarction. With acute torsion, the condition can be confused with appendicitis or ovarian torsion. Other clinical symptoms include nausea, vomiting, fever, leukocytosis, peritoneal signs, and a palpable mass in the abdomen or pelvis [3].

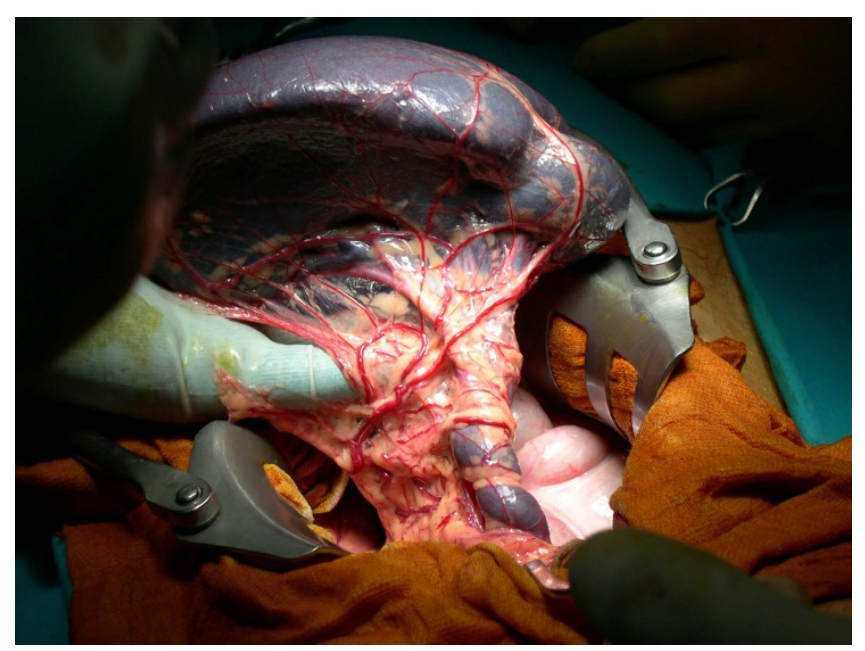

Figure I

The spleen at the opening of the abdomen.

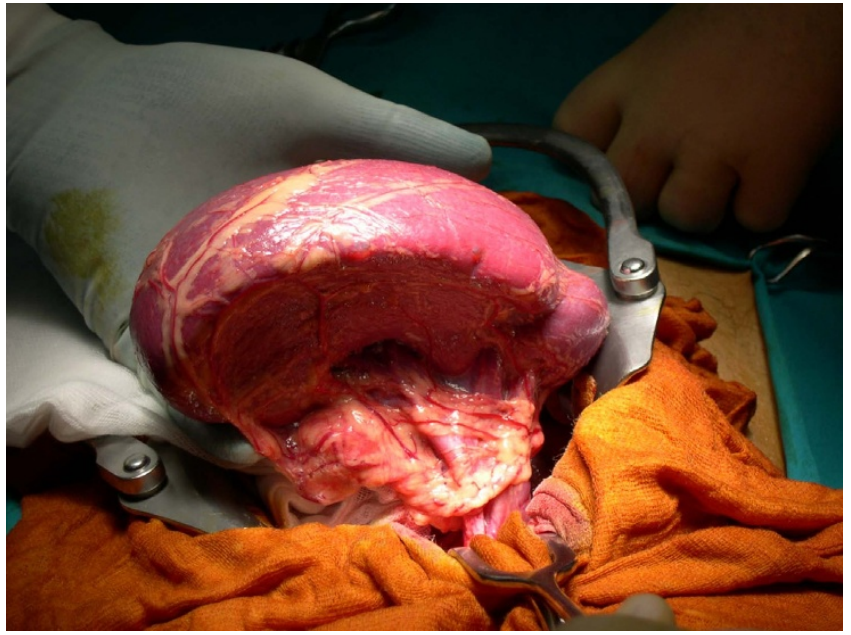

Figure 2

The spleen after the derotation.

For the definitive diagnosis of a wandering spleen, various imaging techniques, including plain radiography, barium enema, scintigraphy, gray-scale sonography, Doppler ultrasonography, CT, and angiography have been used [4].

Historically, splenectomy has been the treatment for symptomatic wandering spleen. With increasing appreciation for the importance of the spleen in reticuloendothelial function, there has been renewed interest in splenopexy. However, in cases of splenic torsion with infarction, splenectomy is required. Attention to vaccination for encapsulated organisms should be performed, usually 1 to 2 weeks after splenectomy [5].

\section{Consent}

Written informed consent was obtained from the patient's mother for publication of this case report and accompanying images. A copy of the written consent is available for review by the Editor-in-Chief of this journal.

\section{Competing interests}

The authors declare that they have no competing interests.

\section{Authors' contributions}

EM recorded the patient data and took the photos. RM and LM performed the intervention, and FF was the major contributor in writing the manuscript. All authors read and approved the final manuscript.

\section{References}

I. Fujiwara $\mathrm{T}, \mathrm{Takehara} \mathrm{Y}$, Isoda $\mathrm{H}$, et al:: Torsion of the wandering spleen: CT and angiographic appearance. J Comput Assist Tomogr 1995, 19:84-86.

2. Sheflin JR, Lee CM, Kretchmar KA: Torsion of wandering spleen and distal pancreas. AJR Am J Roentgenol I984, I 42:I00-I0I. 
3. Herman TE, Siegel MJ: CT of acute splenic torsion in children with wandering spleen. AJR Am J Roentgenol I99I, I56:I5I-I53.

4. Danaci M, Belet U, Yalin T, et al.: Power Doppler sonographic diagnosis of torsion in a wandering spleen. J Clin Ultrasound 2000, 28:246-248.

5. Soleimani M, Mehrabi A, Kashfi A, Fonouni H, Büchler MW, Kraus TW: Surgical treatment of patients with wandering spleen: report of six cases with a review of the literature. Surg Today 2007, 37(3):26I-9.

Publish with Bio Med Central and every scientist can read your work free of charge

"BioMed Central will be the most significant development for disseminating the results of biomedical research in our lifetime. "

Sir Paul Nurse, Cancer Research UK

Your research papers will be:

- available free of charge to the entire biomedical community

- peer reviewed and published immediately upon acceptance

- cited in PubMed and archived on PubMed Central

- yours - you keep the copyright

Submit your manuscript here:

http://www.biomedcentral.com/info/publishing_adv.asp 